\title{
Nonlinear forecasting of Freight Volume based on Elman Network Model
}

\author{
Zhen Meng ${ }^{1}$, Huiyu Zhou ${ }^{1, *}$ \\ ${ }^{1}$ School of Economics and Management, Beijing Jiaotong University, Beijing, China
}

\begin{abstract}
Changes in the demand for bulk cargo will have a significant impact on the industrial structure and transportation development planning, and trains and cargo ships are the main means of bulk cargo transportation. Accurately predicting the volume of bulk cargo transportation can be used to support transportation system management, such as operation planning and route selection design. This study uses the Elman model to conduct empirical analysis, predict the changing trend of bulk cargo transportation, and provide data reference for the formulation of transportation development plans.
\end{abstract}

\section{Introduction}

Compared with other modes of transportation, railways are minimally affected by geography and climate, and have the advantages of strong adaptability, strong transportation capacity, fast transportation speed, low transportation cost, high safety factor and low environmental pollution. Therefore, railways are responsible for most of China's long-distance cargo transportation and are one of the main modes of transportation in China's comprehensive transportation system [1]. As an important connection point between land and sea transportation, the port is not only the main mode of transportation of goods in the port industrial zone, but also an important port for the collection and distribution of inland goods. Therefore, the port also assumes the important responsibility of bulk cargo transportation [2].

Bulk cargo is the basic means of production and is related to the economic foundation of the region. Changes in demand for bulk goods will have a significant impact on the industrial structure and logistics development planning [3]. Freight volume forecasting is a key factor for the transportation sector to formulate efficient operation strategies. Inaccurate freight volume forecasts will cause problems such as waste of traffic resources and excessive transportation pressure. A reasonable and effective forecasting method is the key element for obtaining accurate freight volume forecasting results. According to related literature [4]-[7], neural network with its strong self-learning ability has a good performance in the forecasting accuracy of freight volume.

\section{Data selection and acquisition}

This study summarizes the categories of bulk goods transported by railways and ports through related research [8]. Due to the different characteristics of goods, the categories of bulk goods transported by railways and ports are slightly different. Railway transportation mainly includes: coal, petroleum, steel, non-ferrous metals, and metal ore. Port transportation mainly includes: coal, petroleum, natural gas, and metal ore. The research of railway freight volume in this study selects data from 1999 to 2018 in the 20 years. The use of ports for the transportation of bulk cargo has risen late, so the port freight volume selected the 10-year data from 2010 to 2019 for research and forecast analysis. All data in this study come from the National Bureau of Statistics and the Statistical Bulletin of the Development of the Transportation Industry.

\section{Empirical Analysis}

\subsection{Elman model construction}

The mathematical expression of Elman model is:

$$
\begin{gathered}
\mathrm{y}(\mathrm{k})=\mathrm{g}\left(\mathrm{w}_{3} \mathrm{x}(\mathrm{k})\right) \\
\mathrm{x}(\mathrm{k})=\mathrm{f}\left(\mathrm{w}_{1} \mathrm{x}_{\mathrm{c}}(\mathrm{k})+\mathrm{w}_{2}(\mathrm{u}(\mathrm{k}-1))\right) \\
\mathrm{x}_{\mathrm{c}}(\mathrm{k})=\mathrm{x}(\mathrm{k}-1)
\end{gathered}
$$

In the formula, $\mathrm{u}(\mathrm{k})$ represents the input layer vector, $x(k)$ represents the hidden layer vector, $y(k)$ represents the output layer vector, and $\mathrm{x}_{\mathrm{c}}(\mathrm{k})$ represents the inherited layer vector, that is, the feedback state vector. $\mathrm{w}_{3}$ represents the connection weight from the hidden layer to the output layer, $\mathrm{w}_{2}$ represents the connection weight from the input layer to the hidden layer, and $\mathrm{w}_{1}$ represents the connection weight from the inheriting layer to the hidden layer. The activation function of the hidden layer neuron is expressed by $f(\cdot)$, the sigmoid function is used, and the output layer transfer function is expressed by $\mathrm{g}(\cdot)$.

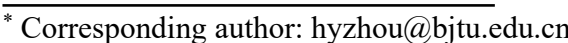


The purpose of training and learning of the Elman model is to correct the connection weights and thresholds in the neural network through the difference between the predicted results of the model output and the actual output results, and finally achieve the minimum sum of squared errors of the output layer. The error function of the Elman model is as follows:

$$
E(t)=\left(y_{k}(t)-y(t)\right)^{T}\left(y_{k}(t)-y(t)\right) / 2
$$

In order to reduce the magnitude difference of the data, prevent oversaturation of neurons caused by excessive values, and speed up the convergence of the Elman neural network, it is necessary to normalize the data in advance. The normalization formula is:

$$
\mathrm{x}^{*}=\left(\mathrm{x}-\mathrm{x}_{\min }\right) /\left(\mathrm{x}_{\max }-\mathrm{x}_{\min }\right)
$$

In the formula, $x_{\min }$ represents the minimum value of the input sample, $x_{\max }$ represents the maximum value of the input sample, and $x^{*}$ represents the input value after normalization. When outputting the results, denormalization is required. This part is implemented by the mapminmax function in MATLAB.

Table1. Prediction results of the rail freight volume of bulk cargo without economic crisis (unit: ten thousand ton)

\begin{tabular}{ccccc}
\hline Years & Coal & Petroleum & $\begin{array}{c}\text { Steel and non- } \\
\text { ferrous metals }\end{array}$ & Metal ore \\
\hline 2019 & 195740.1 & 12036 & 20303 & 42959 \\
2020 & 217130.8 & 12353 & 21536 & 43741 \\
2021 & 237275 & 12554 & 22299 & 44300 \\
2022 & 254200 & 12692 & 22802 & 44698 \\
2023 & 266531 & 12794 & 23156 & 44982 \\
2024 & 274329 & 12873 & 23418 & 45184 \\
2025 & 278848 & 12936 & 23619 & 45327 \\
\hline
\end{tabular}

Using the Elman model to predict the volume of bulk cargo rail freight from 2020 to 2025 in the event of an economic crisis in 2020 is shown in Table 2.

Table2. Prediction results of the rail freight volume of bulk cargo under the economic crisis (unit: ten thousand ton)

\begin{tabular}{ccccc}
\hline Years & Coal & Petroleum & $\begin{array}{c}\text { Steel and non- } \\
\text { ferrous metals }\end{array}$ & Metal ore \\
\hline 2019 & 195740.1 & 12036 & 20303 & 42959 \\
2020 & 217130.8 & 12353 & 21536 & 43741 \\
2021 & 212619 & 11871 & 19985 & 42355 \\
2022 & 233167.1 & 12254 & 21339 & 43308 \\
2023 & 250842.8 & 12489 & 22175 & 43991 \\
2024 & 264104 & 12674 & 22717 & 44478 \\
2025 & 272738 & 12760 & 23095 & 44825 \\
\hline
\end{tabular}

The forecast results of the port freight volume of bulk cargo from 2020 to 2025 realized by using the Elman model in the absence of an economic crisis are shown in Table 3.
This study uses the Elman neural network to make predictions [9]. This study uses $80 \%$ of the sample data as the training set and trains through the Elman neural network. Use $20 \%$ of the data as the test set to test the fit and predictive effect of the model. Set the training goal of the neural network to 0.001 , the learning rate to 0.1 , and the number of iterations to 1000 . This section uses MATLAB software to achieve. According to the changing trend of freight volume, this paper sets up two situations with or without economic crisis, and establishes models for training respectively. Then, according to the error between the real value and the predicted value, it performs inverse feedback to update the weight of each connection line in the neural network and the preference of each layer.

\subsection{Model prediction results}

Using the Elman model to predict the volume of bulk cargo railway freight from 2020 to 2025 in the absence of an economic crisis is shown in Table 1. 
Table3. Prediction results of port freight volume of bulk cargo without economic crisis (unit: ten thousand ton)

\begin{tabular}{llcc}
\hline Years & Coal & Petroleum and Natural gas & Metal ore \\
\hline 2020 & 287280 & 131250 & 238050 \\
2021 & 318070 & 137020 & 254160 \\
2022 & 344060 & 140210 & 264890 \\
2023 & 356940 & 140710 & 270070 \\
2024 & 361250 & 140900 & 272210 \\
2025 & 362460 & 140960 & 274050 \\
\hline
\end{tabular}

The forecast results of the port freight volume of bulk model in the event of an economic crisis in 2020 are shown in Table 4. cargo from 2020 to 2025 realized by using the Elman

Table4. Prediction results of the port freight volume of bulk cargo under the economic crisis (unit: ten thousand ton)

\begin{tabular}{cccc}
\hline Years & Coal & Petroleum and Natural gas & Metal ore \\
\hline 2020 & 287280 & 131250 & 238050 \\
2021 & 270520 & 128890 & 237040 \\
2022 & 295670 & 129980 & 245050 \\
2023 & 325630 & 130880 & 255150 \\
2024 & 347390 & 131620 & 264560 \\
2025 & 358170 & 131970 & 270020 \\
\hline
\end{tabular}

\section{Discussion}

Table5. Forecast results of bulk cargo transport volume in 2025 (unit: ten thousand ton)

\begin{tabular}{cccc}
\hline \multicolumn{2}{c}{ Predictive indicators } & no economic crisis & an economic crisis \\
\hline & Coal & 278848 & 272738 \\
$\begin{array}{c}\text { rail freight volume } \\
(\text { unit: ten thousand } \\
\text { ton })\end{array}$ & Petroleum & Steel and non- \\
ferrous metals & Metal ore & 23619 & 12760 \\
& Coal & 45327 & 23095 \\
\hline $\begin{array}{c}\text { port freight volume } \\
(\text { unit: ten thousand } \\
\text { ton })\end{array}$ & $\begin{array}{c}\text { Petroleum and } \\
\text { Natural gas } \\
\text { Metal ore }\end{array}$ & 362460 & 34825 \\
\hline
\end{tabular}

(1) Characteristics of total freight volume

Both rail freight volume and port freight volume have shown an upward trend. In the railway freight volume, the growth rate of coal freight volume is higher than that of steel and non-ferrous metals, and higher than that of oil and metal ore. The highest growth rate of port freight demand is coal, followed by metal ore, and petroleum and natural gas has a lower growth rate.

(2) Freight structure characteristics

In the statistics of railway and port freight volume, coal, oil and gas and metal ore all use ports as the main mode of transportation, but the distribution ratios are different. The freight structure of coal transportation in 2025 shows the characteristics of port $(56.77 \%)>$ railway $(43.23 \%)$; the freight structure of oil and gas transportation shows the characteristics of port $(91.10 \%)>$ railway $(8.90 \%)$; the freight structure of metal ore transportation shows the characteristics of port $(85.76 \%)>$ railway $(14.24 \%)$.

(3) Main features of bulk cargo transportation

First of all, the share of railway transportation and port transportation is stable without significant changes. Furthermore, the cargo transportation volume of coal, oil 
and gas and metal ore is showing a steady upward trend. Port transportation is the main mode of transportation. In the transportation of oil and gas and metal ore, port transportation accounts for about $90 \%$ of the share.

\section{Conclusions and recommendations}

According to the prediction of the volume of bulk cargo by the Elman model, it can be seen that the volume of freight is generally on a continuous upward trend. However, China's economic development is in a special period, the economic growth rate is slowing down, and the freight volume will inevitably have some fluctuations. From the perspective of external factors, the layout of China's productivity is changing, the tertiary industry is rapidly rising, the bulk cargo market is sluggish, and other modes of transportation are also competing with railway cargo transportation and port cargo transportation in different ways. From the perspective of internal factors, the freight rate mechanism is not flexible enough, and the timeliness of freight and transportation quality need to be improved. In summary, bulk cargo should implement integrated management of the logistics supply chain and establish a market-oriented freight rate mechanism to better adapt to the rapid changes in the Chinese market environment.

\section{References}

1. Zhu R, Zhou H. Railway Passenger Flow Forecast Based on Hybrid PVAR-NN Model[C]// 2020 IEEE 5 th International Conference on Intelligent Transportation Engineering (ICITE). IEEE, 2020.

2. MA Qing, CHEN Yanjin. Study on Forecast of Freight Transport Volume of Port Railway Industrial Siding [J]. Railway Freight Transport,2016,34(03):38-42.

3. $\mathrm{Xu}$ Ying. Research on Freight Volume Forecast of Chongqing Bulk Commodities Based on input-output Model [D]. Chongqing Jiaotong University,2015.

4. Guo Y H, Chen Z Y, Feng F L , et al. Railway Freight Volume Forecasting of Neural Network Based on Economic Cycles[J]. Tiedao Xuebao/journal of the China Railway Society, 2010, 32(5):1-6.

5. Zhao C, Liu K, Li D S, Freight Volume Forecast Based on GRNN[J]. Journal of the China Railway Society, 2004.

6. Zhang Y, Study on Transportation Demand Forecast Using Neural Network Model. Journal of Southwest Jiaotong University, 1999.

7. GENG Liyan, ZHANG Tianwei, ZHAO Peng. Forecast of Railway Freight Volumes Based on LSSVM with Grey Correlation Analysis [J]. Journal of the China Railway Society, 2012, 034(003):1-6.

8. A P L, A Y L, B Q X, et al. Application of a hybrid quantized Elman neural network in short-term load forecasting - ScienceDirect[J]. International Journal of Electrical Power \& Energy Systems, 2014, 55(2):749-759.
9. Brewer A M, Button K J, Hensher D A. [Handbooks in Transport] Handbook of Logistics and SupplyChain Management Volume 2 || Bulk Commodity Logistics[J]. 2008， 10.1108/9780080435930:441454. 